OPEN ACCESS

Edited by:

Guangxu Liu,

Zhejiang University, China

Reviewed by:

Xiaonan Wang,

Chinese Research Academy of Environmental Sciences, China

Yan Zhang,

Nanjing University, China

*Correspondence: Jing Hou

houjing@ncepu.edu.cn

Specialty section: This article was submitted to

Aquatic Physiology,

a section of the journal

Frontiers in Marine Science

Received: 22 August 2021 Accepted: 21 September 2021

Published: 11 October 2021

Citation:

Gao N, Huang Z, Xing J, Zhang S and Hou J (2021) Impact

and Molecular Mechanism of Microplastics on Zebrafish in the Presence and Absence

of Copper Nanoparticles.

Front. Mar. Sci. 8:762530. doi: 10.3389/fmars.2021.762530

\section{Impact and Molecular Mechanism of Microplastics on Zebrafish in the Presence and Absence of Copper Nanoparticles}

\author{
Ning Gao, Zhihui Huang, Jianing Xing, Siyi Zhang and Jing Hou* \\ MOE Key Laboratory of Resources and Environmental Systems Optimization, College of Environmental Science \\ and Engineering, North China Electric Power University, Beijing, China
}

The adverse effects of microplastics (MPs) in aquatic environments have attracted increasing attention and posed health risks along with nanomaterials. Therefore, the toxic effects of polystyrene microplastics (PS-MPs) with different particle sizes $(0.07,0.7$ and $7 \mu \mathrm{m}$ ) on zebrafish in the presence and absence of copper nanoparticles (Cu-NPs) were evaluated. The acute toxicity of MPs on zebrafish was $7 \mu \mathrm{m}>0.07 \mu \mathrm{m}>0.7 \mu \mathrm{m}$. Both 0.07 and $7 \mu \mathrm{m}$ MPs acted on chromosomes and significantly affected cell cycle process by affecting palmitoyl hydrolase activity; while $0.7 \mu \mathrm{m}$ MPs acted on extracellular space and significantly affected the activity of endopeptidase inhibitor to affect the cholesterol transport. And 0.07 and $7 \mu \mathrm{m}$ MPs dominantly affected "cell cycle" pathway by inhibiting DNA replication, delaying the progression of $S$ phase and G2/M phase, and affecting the accurate arrangement and separation of chromosomes; while the $0.7 \mu \mathrm{m}$ MPs activated numerous platelets to aggregate and adhere in damaged parts, enhanced the coagulation function of platelets, and promoted the formation of fibrin clots, thus abnormally activating the "hemostasis" pathway. The presence of CuNPs significantly changed the toxicity-related pathways induced by $7 \mu \mathrm{m}$ MPs from "cell cycle" into "hemostasis," but not for the smaller-sized MPs (0.07 and $0.7 \mu \mathrm{m})$. The combined exposure of Cu-NPs and $7 \mu \mathrm{m}$ MPs acted on the extracellular region and significantly affected cholesterol transport by affecting the activity of cholesterol transporters. This study provides theoretical insights for the health risks of MPs to aquatic species and even humans in the actual ecosystem.

Keywords: nanoparticle (NP), toxicity, microplastic (MP), zebrafish, hemostasis, cell cycle

\section{INTRODUCTION}

Microplastics (MPs), generally defined as plastic fragments, fibers and particles smaller than $5 \mathrm{~mm}$ in size, have attracted widespread attention due to their ubiquity and persistence (Machado et al., 2018; Hartmann et al., 2019). It is of great concern that aquatic organisms with low feeding selectivity are likely to ingest these plastic particles because of their small size (Geyer et al., 2017), accompanying with adverse effects (Wright et al., 2013; Lehner et al., 2019). It has been demonstrated that MPs can be ingested by various aquatic species, including zooplankton 
(Cole et al., 2019), crustaceans (Yu et al., 2018), bivalves (Zhang et al., 2020), fish (Foley et al., 2018), mammals (Sanganyado et al., 2018), etc.; previous reports also have confirmed that MPs uptake can cause a series of adverse effects on aquatic organisms, such as reduced survival rate (Lee et al., 2013), intestinal damage (Gu et al., 2020), loss of energy reserves (Watts et al., 2015), oxidative stress (Choi et al., 2018; Ding et al., 2020), reduced food intake (Cole et al., 2019; Lehner et al., 2019), and growth retardation (Xia et al., 2020). More serious is the transfer of MPs at different trophic levels and that may pose higher associated risks (Bouwmeester et al., 2015). Therefore, it is necessary to effectively identify the behavior of MPs in aquatic environments and their adverse effects on organisms.

It should be mentioned that the aquatic environment in natural state is a complex system containing different types of microparticles (or other pollutants), and thus, the toxicity study of only one type of pollutant may not accurately report its environmental impact. Therefore, more studies have taken into account that MPs can absorb many hazardous contaminants due to their hydrophobic surface and large specific surface area, resulting in combined toxicity (Brennecke et al., 2016; Batel et al., 2018). It has been currently demonstrated that MPs have high adsorption capacity to heavy metals (Brennecke et al., 2016), persistent organic pollutants (POPs) (Batel et al., 2018), antibiotics (Prata et al., 2018) and engineered nanomaterials (NMs) (Schirinzi et al., 2017), and may increase their bioavailability after desorption in organisms (Bakir et al., 2014). Much of the recent concern has concentrated upon the combined effects resulting from MPs and organic pollutants or heavy metals. Yet, little is known about the impact of MPs in the presence of NMs. Both MPs and NMs have accumulated in rivers and coastal areas as many similar processes in the migration and transformation exist like sewage treatment and landfill, thereby providing them with the opportunity to co-exist in aquatic systems (Bouwmeester et al., 2015; Lebreton et al., 2017; Pico et al., 2018). Current studies also have provided evidence that MPs can be used as carriers of silver, $\mathrm{TiO}_{2}$ and other nanoparticles (NPs) in aquatic environments, which are partly attributed to the monolayer adsorption process driven by electrostatic interaction (Fries et al., 2013; Li et al., 2020). Additionally, the particle toxicity effect of MPs on organisms is similar to that of some NMs, so concern is raised that the combined effects of MPs and NMs (Hueffer et al., 2017). Prior work exhibited that when two or more kinds of microparticles were mixed exposed, the effect of interaction may be synergistic, additive or antagonistic. For example, it was revealed that combined exposure of Au-NPs and MPs at a high concentration was more toxic to Tetraselmis chuii than single exposures (Davarpanah and Guilhermino, 2019). In another study, it has already reported that polystyrene microplastics (PS-MPs) could enhance the accumulation of $\mathrm{Cu}$ in zebrafish tissues and exacerbate $\mathrm{Cu}$ toxicity as they acted as carriers for $\mathrm{Cu}$ ions (Qiao et al., 2019; Bernardes Roda et al., 2020). On the contrary, microsized polyvinyl chloride (mPVC) particles reduced the toxicity of $\mathrm{Cu}$ NPs to the microalgae Skeletonema costatum by adsorption of $\mathrm{Cu}$ ions and mutual agglomeration with Cu-NPs (Zhu et al., 2020). However, conflicting results have been found for the combined toxicity of MPs and NMs, and the mechanism of toxicity has not been clearly explained at the molecular level. Hence, it warrants further study the potential toxicity mechanism of MPs and speculate related ecological impacts.

In the present research, PS-MPs and Cu-NPs have been selected because of their extensive commercial and industrial use and high accumulation in aquatic environments (Qiao et al., 2019; Wu et al., 2020). The purposes of this study were (1) to verify the impact of PS-MPs with different particle sizes $(0.07,0.7$, and $7 \mu \mathrm{m}$ ) on zebrafish (Danio rerio) in the presence and absence of Cu-NPs; (2) to reveal their molecular toxicity mechanisms. In general, this study investigated the combined toxicity mechanism of MPs and NPs to aquatic vertebrates at the transcriptome level, which can better understand the health risks of MPs to aquatic ecosystems.

\section{MATERIALS AND METHODS}

\section{Zebrafish Husbandry and Acclimation}

The zebrafish $(0.19 \pm 0.03 \mathrm{~g}$ in weight, $27 \pm 2 \mathrm{~mm}$ in body length) were maintained in tap water with ultraviolet (UV) sterilized and fully aerated (culture water) under the following conditions: temperature $24 \pm 1^{\circ} \mathrm{C}$, photoperiod 14: $10 \mathrm{~h}$ (light: dark), $\mathrm{pH}$ $7.3 \pm 0.5$, dissolved oxygen $6.7 \pm 0.4 \mathrm{mg} / \mathrm{L}$, electrical conductivity $0.287 \pm 0.004 \mathrm{mS} / \mathrm{cm}$, water hardness $188 \pm 5 \mathrm{mg} / \mathrm{L} \mathrm{CaCO}_{3}$, and acclimated for 2 weeks before the exposure experiment. The fish were fed twice a day and dead fish were removed in time. All experiments were performed in accordance with the laboratory animal guidelines.

\section{Preparation of PS-MPs and Cu-NPs}

The non-functionalized PS microbeads $(2.5 \% \mathrm{w} / \mathrm{v}, 10 \mathrm{~mL})$ with three different sizes $(0.07,0.7,7 \mu \mathrm{m})$ were purchased from Tianjin BaseLine ChromTech Research Centre (Tianjin, China). The $50 \mathrm{~nm} \mathrm{Cu-NPs} \mathrm{was} \mathrm{obtained} \mathrm{from} \mathrm{Beijing} \mathrm{Deke}$ Daojin Science and Technology Co., Ltd. (Beijing, China). The dispersion solutions of PS-MPs (0.07 $\mu \mathrm{m}$ MPs, $0.7 \mu \mathrm{m}$ MPs, $7 \mu \mathrm{m} \mathrm{MPs}$ ) and $\mathrm{Cu}-\mathrm{NPs}$ were diluted with deionized water and sonicated for $30 \mathrm{~min}$ as the stock solutions. The specific experimental solutions were obtained by diluting the stock solutions with culture water. The morphology and size of PSMPs and $\mathrm{Cu}-\mathrm{NPs}$ were characterized by transmission electron microscope (TEM) (Hitachi, H-7500, Japan) at an accelerating voltage of $80 \mathrm{kV}$. Dynamic light scattering (DLS; Zetasizer nano series, Malvern Instruments Ltd., United Kingdom) was used to determine the hydrodynamic diameters and zeta potentials of PS-MPs and Cu-NPs in culture water after 0 and 96 h. The composition of PS-MPs was determined by Fourier transform infrared (FTIR) spectroscopy with a Nicolet 330 spectrophotometer (Thermo Electron Corp., United States).

\section{Acute Toxicity Tests}

Acute toxicity tests were subjected in accordance with the Organization for Economic Cooperation and Development (OECD) guidelines 203 (OECD., 2019). The control group only contained culture water. Exposure solutions were prepared by 
adding deionized water to the four stock solutions to obtain the final exposure concentration gradients: $0.07 \mu \mathrm{m}$ MPs (70, 80, 90, 95, $100 \mathrm{mg} / \mathrm{L}), 0.7 \mu \mathrm{m}$ MPs (80, 90, 100, 105, $110 \mathrm{mg} / \mathrm{L})$, $7 \mu \mathrm{m}$ MPs (70, 80, 90, 100, $110 \mathrm{mg} / \mathrm{L}), \mathrm{Cu}-\mathrm{NPs}(1.0,1.5,2.0$, $2.5,3.0,4.0 \mathrm{mg} / \mathrm{L})$. Ten acclimated zebrafish were randomly placed in each concentration group, which was performed in triplicates. The mortality of zebrafish and the physicochemical parameters of the exposure solutions were recorded daily during the experiment. The median lethal concentration $\left(\mathrm{LC}_{50}\right)$ of each pollutant on zebrafish was calculated by probit method. In addition, subsequent exposure tests for transcriptomics analysis were performed using $1 / 2 \mathrm{LC}_{50}$ of each pollutant, and seven groups were set up: (1) control group (culture water alone); (2) $0.07 \mu \mathrm{m}$ MPs; (3) $0.7 \mu \mathrm{m}$ MPs; (4) $7 \mu \mathrm{m}$ MPs; (5) Cu$\mathrm{NPs}+0.07 \mu \mathrm{m}$ MPs; (6) Cu-NPs + $0.7 \mu \mathrm{m} \mathrm{MPs}$; (7) $\mathrm{Cu}-$ NPs $+7 \mu \mathrm{m}$ MPs. After $96 \mathrm{~h}$, zebrafish samples from the above seven groups were rapidly frozen in liquid nitrogen and stored at $-80^{\circ}$ for transcriptome sequencing.

\section{RNA-Sequencing}

Total RNA was extracted from each zebrafish sample by TRIzol ${ }^{\circledR}$ Reagent (Invitrogen, California, United States) according to the manufacturer's instructions, including the following operations: homogenizing samples, phase separation, RNA precipitation, RNA wash and RNA resuspension. Qualified Total RNA was quantified with Qubit RNA Assay Kit (Invitrogen, California, United States) and tested with Agilent 2100 Bioanaylzer (Agilent Technologies, California, United States). The mRNA was enriched using beads with oligod (T) and then mixed with the fragment buffer to fragment the mRNA. Two strands of cDNA were then synthesized successively using random primers and a series of substrates and polymerases. After purifying the second strand with AMPure XP Beads, the ds cDNA repair reaction was performed. Then, the sequencing adapter was ligated to the cDNA fragment for PCR amplification on S1000 ${ }^{\mathrm{TM}}$ Thermal Cycler (Bio-Rad Laboratories, California, United States). And the Agilent 2100 Bioanaylzer and Qubit DNA HS Assay Kit (Invitrogen, California, United States) were used for quality control and quantification of the constructed library. The flowcell and the prepared library were cluster generated (bridge PCR amplification) on the cBot system and subsequently sequenced on the Illumina Novaseq 6000. After the results pass the quality control, the differentially expression genes (DEGs) were compared and analyzed according to the following standards by DESeq 2 method: fold change $=2$ or $=0.5$ and a false discovery rate (FDR) adjusted $p$-value $<0.05$.

\section{Gene Ontology Enrichment Analysis}

The functional significance enrichment analysis of DEGs was performed. All DEGs and background genes were mapped to each term in Gene Ontology (GO) database, ${ }^{1}$ and the number of genes in each term was calculated. The significantly enriched GO terms were selected according to the $p$-value $<0.05$ (hypergeometric test).

${ }^{1}$ http://www.geneontology.org/

\section{Pathway Annotation and Enrichment Analysis}

The KEGG database, ${ }^{2}$ Reactome database ${ }^{3}$ and Panther database ${ }^{4}$ were used to conduct pathway enrichment analysis on the selected DEGs. The significantly enriched pathways were selected adjusting for $p$-value $<0.05$ via hypergeometric test.

\section{Statistical Analysis}

Data were expressed as means \pm standard deviations (SD). Oneway analysis of variance (ANOVA) test was used to evaluate the statistical differences of physical and chemical parameters and experimental results. The statistical analysis of all experimental data was based on SPSS 21.0 software, and the $\mathrm{LC}_{50}$ values of PS-MPs and Cu-NPs on zebrafish were obtained by the probit analysis. The level of statistical significance was set at $p$-value $<0.05$. The experimental data were mapped using Origin 2019 software.

\section{RESULTS AND DISCUSSION}

\section{Microbead Characterization}

FT-IR analysis demonstrated the same chemical composition of the three MPs powders (i.e., polystyrene) (Figure 1A). The representative TEM images exhibited that the three sizes of virgin MPs $(0.07,0.7$, and $7 \mu \mathrm{m})$ were spherical in shape and uniform in size (Figure 1B). Supplementary Table 1 showed that there was no significant change in hydrodynamic sizes and zeta potentials of the three MPs in culture water at $0 \mathrm{~h}$ and $96 \mathrm{~h}$, suggesting that no agglomeration of MPs occurred over time. These results revealed that the three MPs have similar morphology, same chemical composition and little difference in zeta potentials. Taking into consideration all aforementioned, it is reasonable to analyze the impact of particle size on the acute toxicity of PS-MPs.

\section{Acute Toxicity}

The physical and chemical parameters of the exposure solution recorded daily during the experiment were shown in Supplementary File 1. As shown in Figure 2, the toxicity of $\mathrm{Cu}$ NPs to zebrafish was significantly concentration-dependent, and the survival rate was negatively correlated with the concentration. The survival rate of PS-MPs decreased sharply with the increase of concentration at higher concentrations. The $96 \mathrm{~h} \mathrm{LC}_{50}$ values for $\mathrm{Cu}-\mathrm{NPs}, 0.07 \mu \mathrm{m}$ MPs, $0.7 \mu \mathrm{m}$ MPs, and $7 \mu \mathrm{m}$ MPs were 1.951, 93.971, 104.352, $91.379 \mathrm{mg} / \mathrm{L}$, respectively. On the basis of available literature, the impact of MPs on organisms is size-dependent. Generally, in contrast to micron-sized particles, nano-sized particles exhibit the increased toxic effect since nanoplastics have larger specific surface area, stronger ability to penetrate cells, and higher bioavailability (Bouwmeester et al., 2015; Trevisan et al., 2019). For instance, it has been reported that the $0.05 \mu \mathrm{m}$ MPs showed a more deleterious impact on the

\footnotetext{
${ }^{2}$ http://www.genome.jp/kegg/

${ }^{3}$ http://www.reactome.org/

${ }^{4}$ http://www.pantherdb.org/
} 

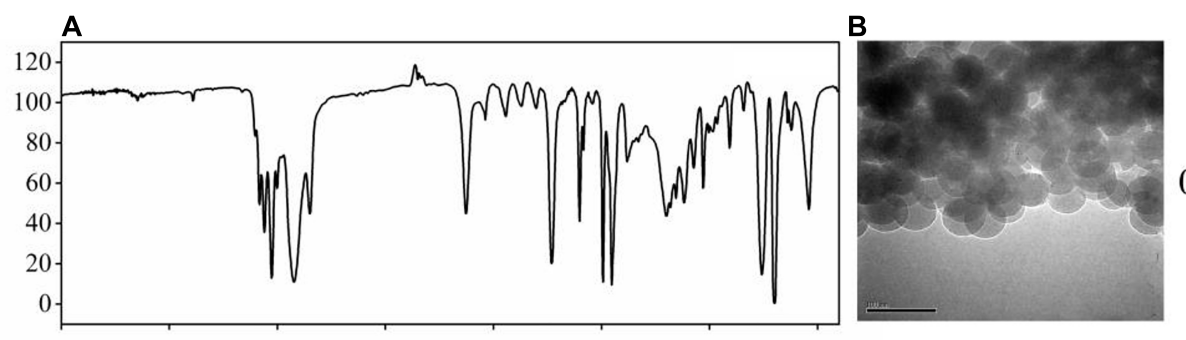

$0.07 \mu \mathrm{m}$ MPs
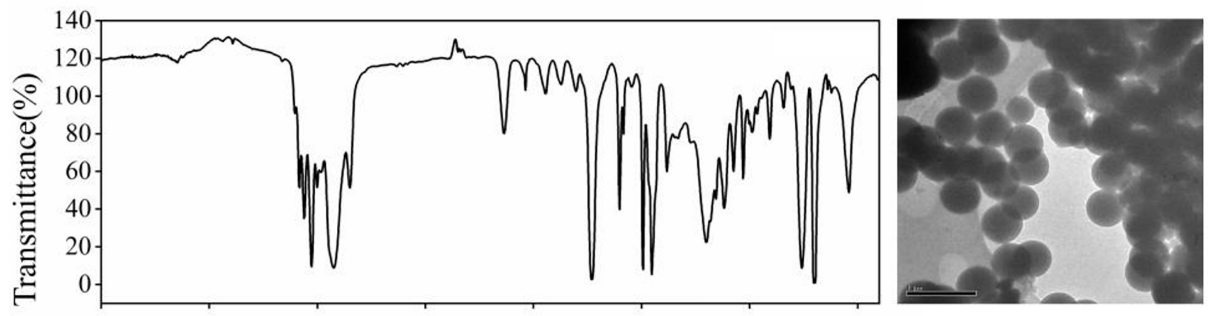

$0.7 \mu \mathrm{m}$ MPs

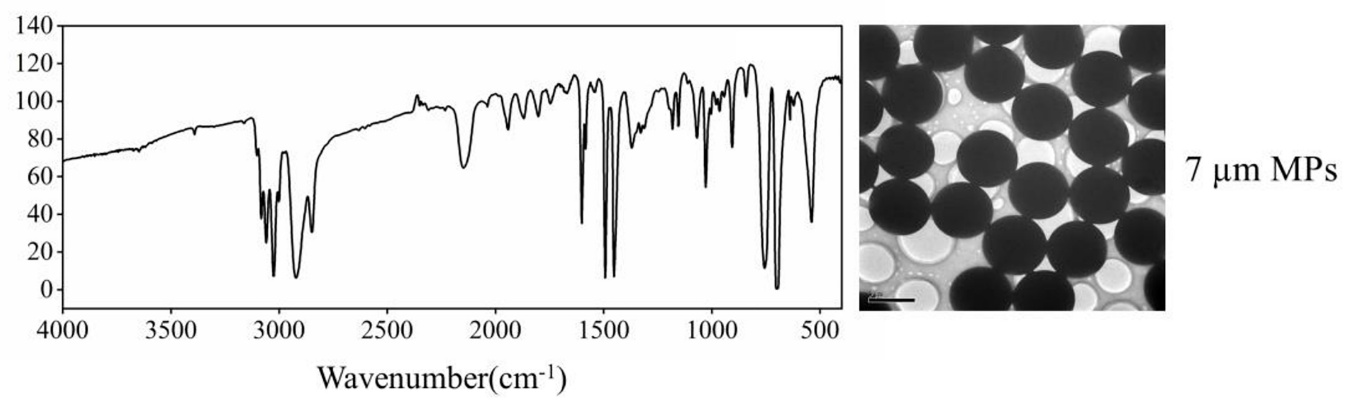

FIGURE 1 | (A) The FTIR spectra showed that three MPs powders $(0.07,0.7$, and $7 \mu \mathrm{m})$ were polystyrene. (B) The TEM images reveal the primary size and morphology of PS-MPs in culture solution.

survival and reproduction of Tigriopus japonicus and Brachionus koreanus than $0.5 \mu \mathrm{m}$ and $6 \mu \mathrm{m}$ MPs (Lee et al., 2013; Jeong et al., 2016). The analogous size-dependent toxicity of $0.1 \mu \mathrm{m}$ and $2 \mu \mathrm{m}$ MPs was noted by Rist et al. (2017), that is, $0.1 \mu \mathrm{m}$ MPs posed greater potential threats like decreasing feeding rate and digestibility, and increasing teratogenicity. Nevertheless, our results indicated that the toxicity of MPs to zebrafish was not monotonously negatively correlated with size. Specifically, the acute toxicity of MPs with three sizes was $7 \mu \mathrm{m}$ MPs $>0.07 \mu \mathrm{m}$ MPs $>0.7 \mu \mathrm{m}$ MPs. Previous studies have also suggested that micro-sized particles can travel into organisms through ingestion or other means to cause biochemical perturbations, and are large enough to induce mechanical damage accompanied by inflammatory responses (Ding et al., 2020). Consistent with our findings, it was found that $5 \mu \mathrm{m}$ MPs provoked higher SOD and CAT activities than $0.07 \mu \mathrm{m}$ MPs in Lu et al. (2016)'s oxidative stress analysis on zebrafish. Additionally, in another study, the $5 \mu \mathrm{m}$ MPs caused more pronounced changes in the expression of metabolism-related genes in the mice offspring with respect to $0.5 \mu \mathrm{m}$ MPs (Luo et al., 2019). Compared with 0.05 and $0.1 \mu \mathrm{m}$ MPs, $1 \mu \mathrm{m}$ MPs induced higher immune responses of hemocyte subpopulations in Mytilus galloprovincialis (Sendra et al., 2020). Perhaps it may be attributed to that organism has a species-specific selection mechanism for micro-sized particles, just as in terms of Sussarellu et al. (2016), oysters preferentially ingested $6 \mu \mathrm{m}$ MPs rather than smaller MPs, and the selection efficiency for uptake of 5 to $6 \mu \mathrm{m}$ MPs could reach $100 \%$. These studies demonstrated that the size and feeding selection of test organisms need to be considered when evaluating the adverse effects of MPs with different sizes, which was approved to be the reason for the greater toxicity triggered by microparticles (Le et al., 2018). Accordingly, the toxicity of $0.07 \mu \mathrm{m}$ MPs may be due to their larger specific surface area and ability to penetrate cells, while the toxicity of $7 \mu \mathrm{m}$ MPs may contribute to the traumatic inflammatory response triggered by feeding selection of zebrafish. In view of this, more researches are needed to enrich and verify the size-dependent toxicity of MPs.

\section{Differentially Expressed Genes Identification}

We chose $1 / 2 \quad \mathrm{LC}_{50}$ as the experimental concentration for transcriptome sequencing since this concentration can be used as the concentration causing the expected genotoxic response (Hansen et al., 2010). A total of 408, 915 and 530 DEGs were responsive to $0.07 \mu \mathrm{m}$ MPs, $0.7 \mu \mathrm{m}$ MPs and $7 \mu \mathrm{m}$ MPs exposures in the absence of Cu-NPs, while 419, 863, and 934 DEGs were identified in the presence of Cu-NPs (versus the control group), respectively (Figures $\mathbf{3 A - F}$ and Supplementary File 2). The majority of the DEGs in $0.07 \mu \mathrm{m} \mathrm{MPs}$ and $7 \mu \mathrm{m}$ 

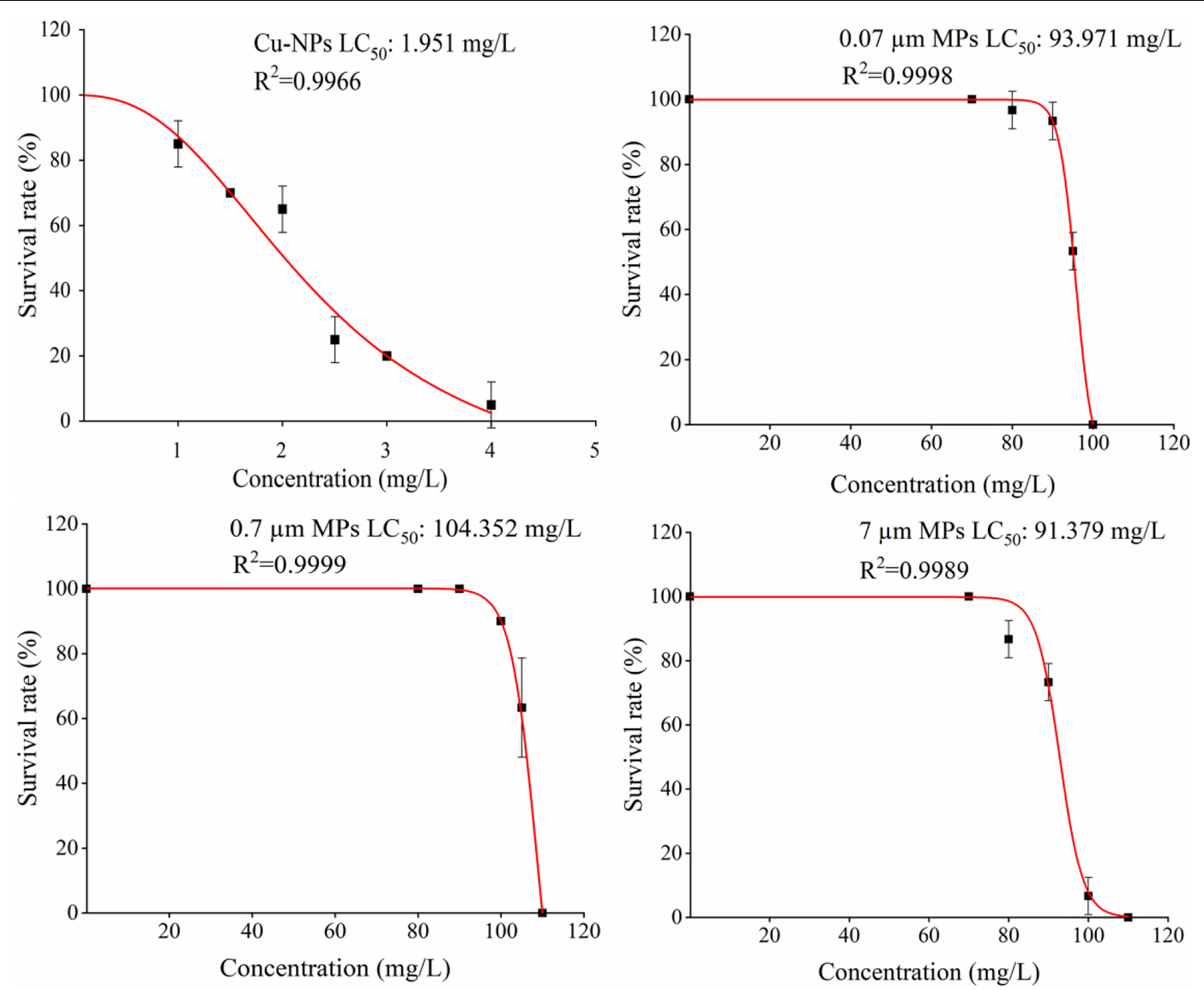

FIGURE 2 | Survival rate curve of zebrafish exposed to Cu-NPs, $0.07 \mu \mathrm{m}$ MPs, $0.7 \mu \mathrm{m}$ MPs and $7 \mu \mathrm{m}$ MPs for $96 \mathrm{~h}$.

MPs were down-regulated, whereas most of the DEGs were upregulated in $0.7 \mu \mathrm{m}$ MPs treatment. Interestingly, the addition of $\mathrm{Cu}-\mathrm{NPs}$ had little effect on the gene expression profiles (including the number and proportion of up-regulated and down-regulated DEGs) induced by 0.07 and $0.7 \mu \mathrm{m}$ MPs treatments, but significantly changed the gene expression profile induced by $7 \mu \mathrm{m}$ MPs treatment, making it dominated by up-regulated DEGs instead of down-regulated DEGs. Furthermore, clustering of each treatment group indicated that the transcription profiles of six treatment groups were roughly two patterns. $0.07 \mu \mathrm{m}$ MPs, $7 \mu \mathrm{m}$ MPs and Cu-NPs $+0.07 \mu \mathrm{m}$ MPs treatments clustered closely, demonstrating that they cause similar forms of toxicity; however, $0.7 \mu \mathrm{m}$ MPs, Cu-NPs $+0.7 \mu \mathrm{m} \mathrm{MPs}$ and $\mathrm{Cu}-$ NPs $+7 \mu \mathrm{m}$ MPs treatments shared a cluster and were close to control group, which suggested the effects of the three treatments did not differ much (Supplementary Figure 1).

\section{Gene Ontology Enrichment Analysis of Differentially Expression Genes}

In order to further understand the potential functional relevance affected by exposures of PS-MPs with and without Cu-NPs, GO enrichment analysis was performed on DEGs of each treatment. The results were assigned to three categories: biological process, cellular component, and molecular function, and the top 10 most significant terms of each category were shown in Supplementary Figure 2 and Supplementary File 3. 0.07 and $7 \mu \mathrm{m}$ MPs acted on the chromosome and significantly affected the cell cycle process by affecting palmitoyl hydrolase activity, and the normal progress of cell cycle was considered to be closely related to of palmitoyl hydrolase activity (Xu et al., 2012); while $0.7 \mu \mathrm{m}$ MPs acted on the extracellular space and significantly affected the activity of endopeptidase inhibitors to affect the cholesterol transport process, which is determined the directional movement of sterols through or between cells (Clay et al., 2015). Interestingly, the presence of Cu-NPs only changed the GO enrichment results of $7 \mu \mathrm{m}$ MPs exposure, but did not significantly change the GO enrichment results affected by $0.07 \mu \mathrm{m}$ MPs and $0.7 \mu \mathrm{m}$ MPs. That is, the combined exposure of $\mathrm{Cu}-\mathrm{NPs}$ and $7 \mu \mathrm{m}$ MPs acted on the extracellular region, and significantly affected the cholesterol transport process by affecting the activity of cholesterol transporters. Worthy to note, the activation of cholesterol transport in three treatments $(0.7 \mu \mathrm{m}$ MPs, Cu-NPs $+0.7 \mu \mathrm{m}$ MPs, and $\mathrm{Cu}-\mathrm{NPs}+7 \mu \mathrm{m}$ MPs) were consistent with those in the juvenile redclaw crayfish exposed to PS-MPs, where the level of total cholesterol in hemolymph increased significantly (Chen et al., 2020). 

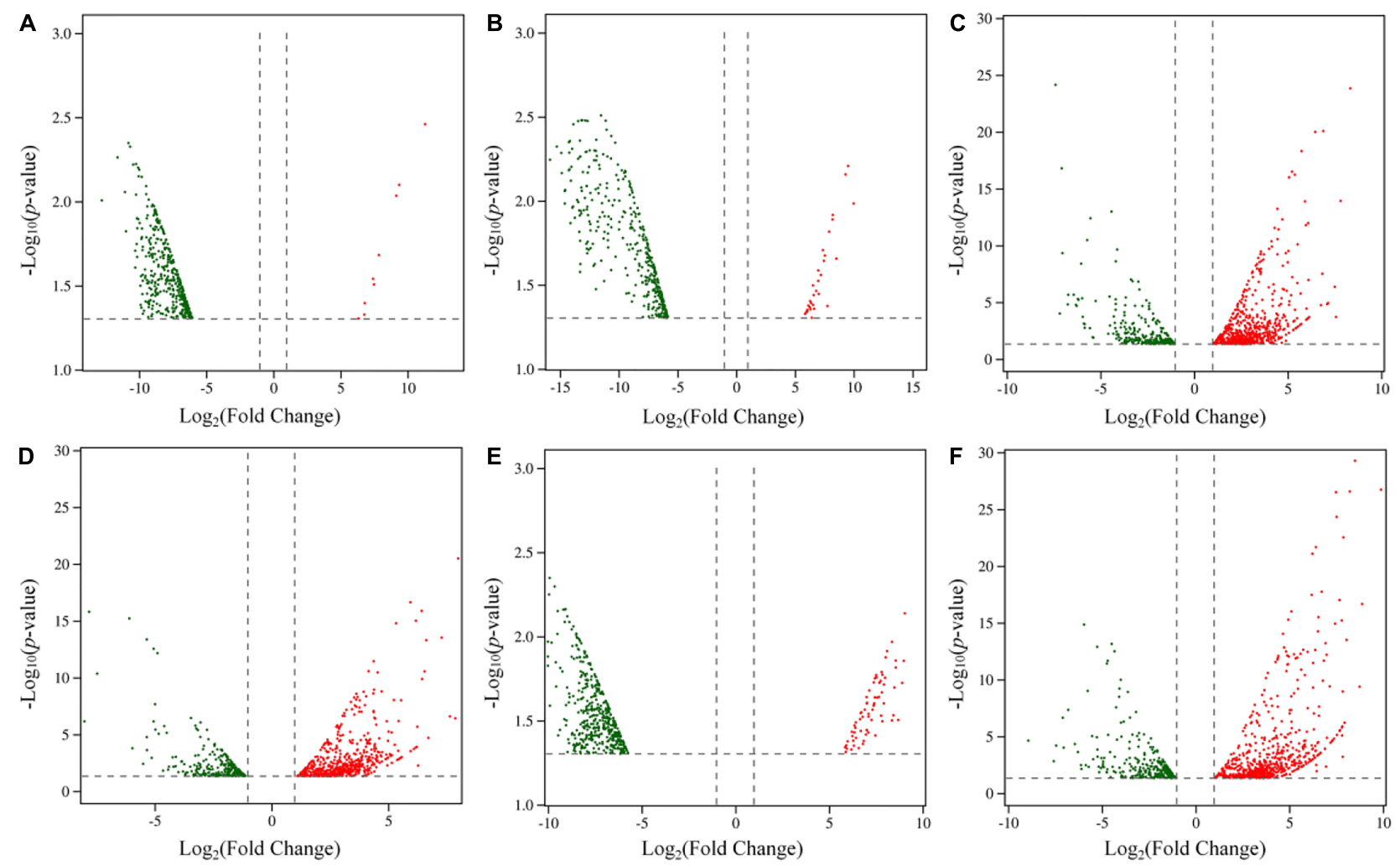

FIGURE 3 | Volcano plots (A-F) were used to illustrate the characteristic of differentially expressed genes (DEGs) in six treatments. (A) $0.07 \mu \mathrm{m}$ MPs. (B) Cu-NPs + $0.07 \mu \mathrm{m}$ MPs. (C) $0.7 \mu \mathrm{m}$ MPs. (D) Cu-NPs $+0.7 \mu \mathrm{m}$ MPs. (E) $7 \mu \mathrm{m}$ MPs. (F) Cu-NPs $+7 \mu \mathrm{m}$ MPs. The X-axis represents the fold change of each gene on a $\log _{2}$ scale (fold change $<0.5$ or fold change $>2$ ). The $y$-axis represents the significance level of each gene on a -log 10 scale $(p$-value $<0.05)$. Each dot represents a gene. Red dots represent up-regulated genes. Green dots represent down-regulated genes.

\section{Pathway-Based Analysis of Differentially Expression Genes}

By profiling the functional involvement of DEGs of each group in the KEGG, Reactome and Panther pathways, we can further gain insights into the association between DEGs and biological pathways. Based on $p$-value, gene number and rich factor, we screened the top 15 pathways that significantly enriched in each treatment (Figure 4 and Supplementary File 4). Interestingly, the results of pathway enrichment analysis have similar sizedependent effects to those of acute toxicity. Specifically, most of the DEGs induced by $0.07 \mu \mathrm{m}$ MPs and $7 \mu \mathrm{m}$ MPs exposures were both involved in cell cycle $\left(p=6.06 \times 10^{-7}\right.$ for $0.07 \mu \mathrm{m}$ MPs, $p=1.37 \times 10^{-9}$ for $7 \mu \mathrm{m}$ MPs) and cell cycle, mitotic $\left(p=6.83 \times 10^{-6}\right.$ for $0.07 \mu \mathrm{m}$ MPs, $p=4.82 \times 10^{-9}$ for $7 \mu \mathrm{m}$ MPs), while the DEGs induced by $0.7 \mu \mathrm{m}$ MPs exposure were enriched in common pathway of fibrin clot formation $\left(p=1.01 \times 10^{-7}\right)$ and platelet degranulation $\left(p=1.88 \times 10^{-7}\right)$, which are both crucial sub-processes of hemostasis. The presence of Cu-NPs only significantly changed the enriched biological pathways of $7 \mu \mathrm{m}$ MPs exposure, i.e., from cell cycle-related pathways to hemostasis-related pathways, while there was no significant change in the enriched pathways of $0.07 \mu \mathrm{m} \mathrm{MPs}$ and $0.7 \mu \mathrm{m}$ MPs. This is because the addition of $\mathrm{Cu}-\mathrm{NPs}$ significantly changed the gene expression profile induced by $7 \mu \mathrm{m}$ MPs, and changed the cellular components, molecular functions and biological processes associated with DEGs. Therefore, we predicted the molecular toxicity mechanisms caused by PS-MPs exposure in the presence or absence of $\mathrm{Cu}$-NPs by explaining the two most significant enrichment pathways "hemostasis" and "cell cycle" screened from six exposure treatments.

\section{Hemostasis}

In our study, the activation of cholesterol transport in three treatments $(0.7 \mu \mathrm{m}$ MPs, Cu-NPs $+0.7 \mu \mathrm{m}$ MPs, and $\mathrm{Cu}-$ NPs $+7 \mu \mathrm{m}$ MPs) based on GO analysis may affect hemostasis as cholesterol plays a crucial role in the activation and adhesion of platelets and the interaction of cells on the vascular walls (Kannel, 2005). Hemostasis is an intricate and effective physiological defense mechanism initiated in response to injured blood vessels (Figure 5) (Jagadeeswaran et al., 2005; Lasne et al., 2006). It is mainly composed of platelet adhesion, coagulation, and fibrinolysis, wherein coagulation and fibrinolysis are two interconnected reaction networks, modulating the formation and dissolution of fibrin clots, respectively (Jagadeeswaran et al., 2005; Medvedev et al., 2010). When acute vascular injury occurs, the vasoconstriction mechanism predominates, and activated platelets adhere to the exposed collagen to promote coagulation (Austin et al., 2011; Berna-Erro et al., 2013). At first, circulating 


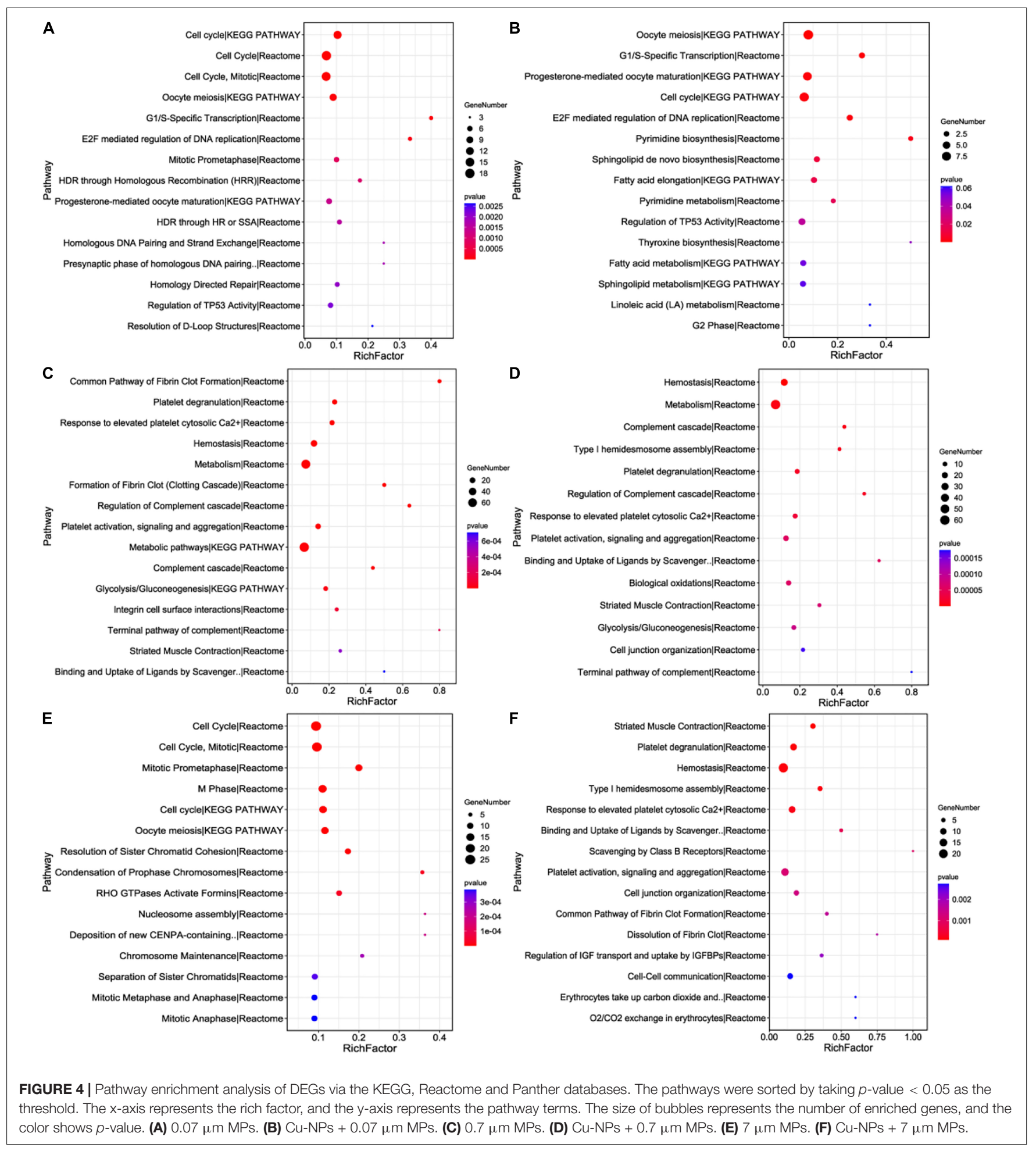

platelets can identify endothelial lesion areas and adhere to the components of the subendothelium (Kannel, 2005). Here they combine with a variety of thrombogenic substrates and interact with the excitatory platelet agonists to ultimately activate themselves (van der Poll and Parker, 2020). Subsequently, a series of signaling reactions will further enhance the adhesion and procoagulant properties of tethered platelets or nearby circulating platelets. Adhered platelets will degranulate and secrete large amounts of stored effector molecules at the injured site in the form of exocytosis, such as dense granules and alpha granules, to regulate the platelet aggregation process through cell signal transduction (Ge et al., 2010; Golebiewska and Poole, 2014; 

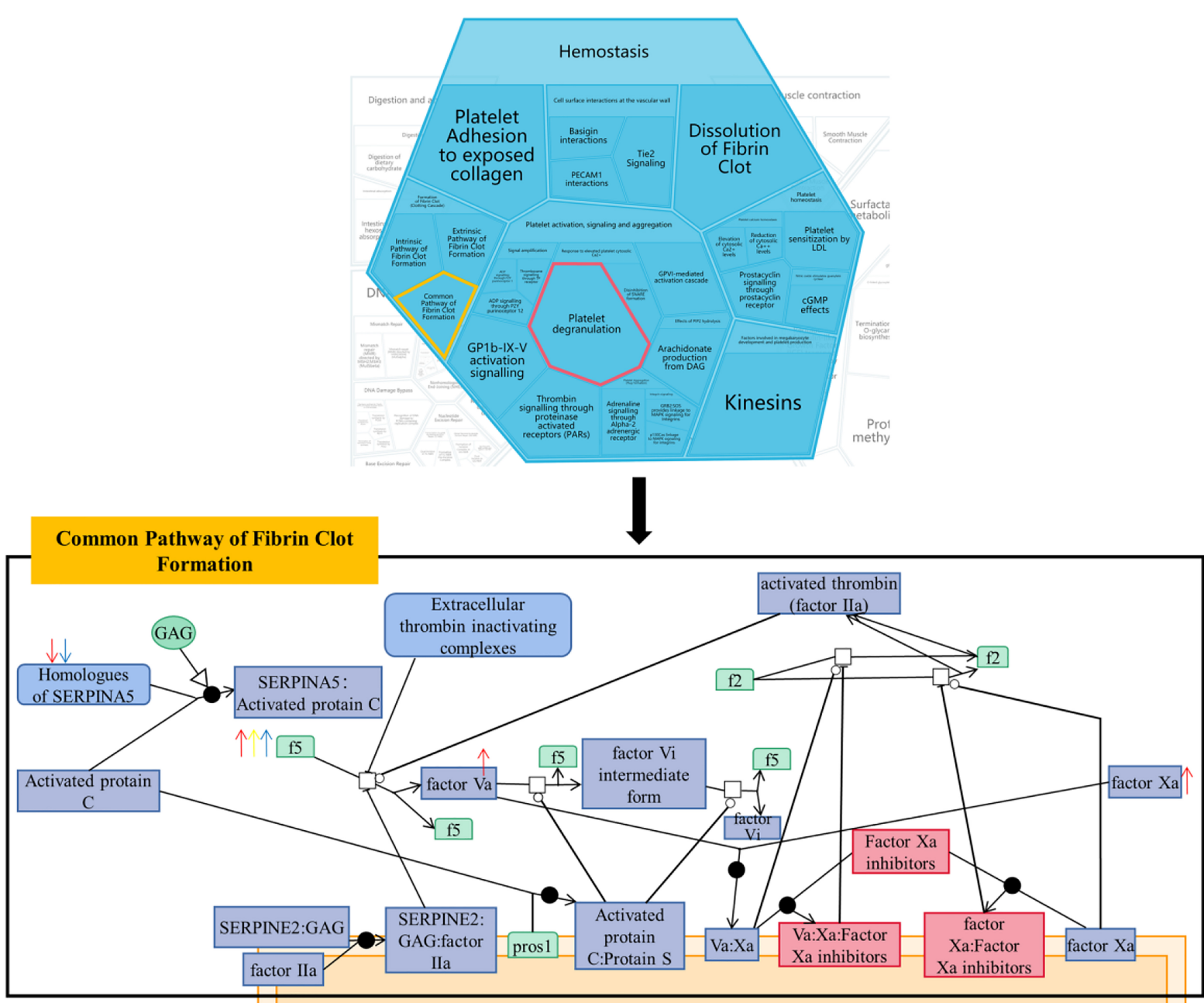

\section{Platelet degranulation}

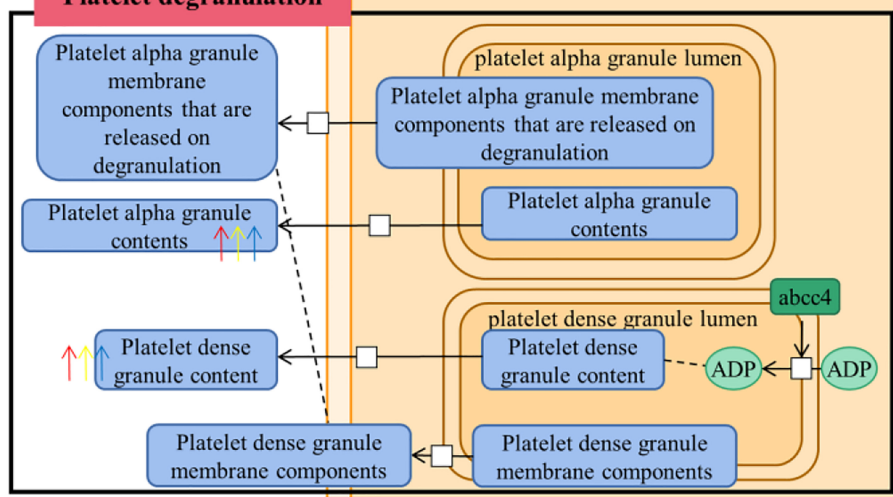

cytoplasm

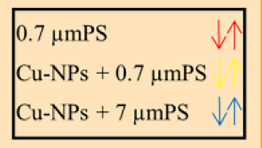

FIGURE 5 | Hemostasis. The platelet degranulation and formation of fibrin clot are the two most representative sub-processes in hemostasis pathway.

Zhang et al., 2018). Our results showed that the abundance of components in platelet dense granules and alpha granules will increase significantly under three exposure conditions $(0.7 \mu \mathrm{m}$ MPs, Cu-NPs $+0.7 \mu \mathrm{m}$ MPs and Cu-NPs $+7 \mu \mathrm{m}$ MPs) due to up-regulated expression of genes encoding them ( $f 5$, serpinal, hgfa, serping1, aldoaa, igf $2 b$, ahsg2, tor $4 a a$, tfa, etc.), which could activate numerous platelets, aggregate and adhere to the damaged part, greatly enhance the coagulation function of platelets, and provide a positive role for the formation of fibrin clots. Previous research has confirmed our results and shown that MPs and 
pollutants could cause plasma membrane damage in different organs of fish typified by significant changes in cholesterol, platelets and other biochemical parameters (Hamed et al., 2019); and it was reported that physical stress caused by direct contact of PS-MPs with fibroblasts and red blood cells would lead to cell membrane damage and hemolysis (Choi et al., 2020). Similarly, exposure to NPs such as mesoporous silica NPs could damage the adhesion of platelets to endothelial cells, significantly increase the platelet adhesion events, lead to uncontrolled platelet aggregation actions, and ultimately promote the formation of blood clots in vivo (Kim et al., 2014).

It is currently believed that the products of each reaction in the formation of fibrin clots are enzymes or cofactors, capable of catalyzing or guiding the subsequent reactions, and consequently the entire process is a cascade reaction (Figure 5). Hence, it is reasonable to infer that the changes in the expression levels of some intermediate products have a great impact on clot formation. The common pathway, as a crucial portion of fibrin clot formation, includes a series of activation events from the formation of activated factors X, V, and XIII to the generation of activated thrombin, and finally fibrinogen is cleaved to form a stable cross-linked complex (Johari and Loke, 2012). Factor Xa catalyzes the conversion of prothrombin into activated thrombin, which in turn activates factor $\mathrm{V}$ into factor Va. Then factors Va and Xa combine on the membrane surface to form a complex that can rapidly activate a large multitude of thrombin to facilitate the conversion of fibrinogen to fibrin (Krupiczojc et al., 2008). Prior work has documented that $f g a, f g b$, and $f g g$ encoding fibrinogen alpha, beta and gamma chains in zebrafish, respectively, are homologous to human fibrinogen gene sequences (Vo et al., 2013). Moreover, protein C inhibitor (SERPINA5) is also a vital factor during hemostasis that can inhibit some coagulation factors, such as prothrombin and factor Xa (Wagenaar et al., 2010). The three treatments $(0.7 \mu \mathrm{m}$ MPs, Cu-NPs $+0.7 \mu \mathrm{m}$ MPs and $\mathrm{Cu}-\mathrm{NPs}+7 \mu \mathrm{m}$ MPs) resulted in the down-regulation of serpina7, an important component of SERPINA5, which weakened inhibitory effect on coagulation factors and reduced the feedback regulation of the coagulation process, indicating that the coagulation function of the organism has been activated. And the overexpression of regulatory factors $\mathrm{X}, \mathrm{V}$, and fibrinogen induced by $0.7 \mu \mathrm{m}$ MPs significantly increased the abundance of substrates and cofactors in the process of fibrin clot formation, and activated the formation of clots in the blood. In the presence of $\mathrm{Cu}-\mathrm{NPs}$, both 0.7 and $7 \mu \mathrm{m}$ MPs caused the up-regulation of fibrinogen and facilitated the formation of fibrin, suggesting that the blood vessels of zebrafish may be damaged and in selfhealing. To be exact, the overexpression of fibrinogen in the above three treatments is the manifestation of zebrafish's acute stress response because fibrinogen is considered as an acute reactant, whose level increases under inflammation and stress to directly affect blood coagulation and platelet aggregation (Khokhlova et al., 2017). And it was reported that the interaction between NPs and fibrinogen could induce blood coagulation under in vitro conditions (Chen et al., 2011). In addition, the treatment of some NPs such as amorphous silica NPs caused acute lethality and abnormal activation of the formation of fibrin clots in mice; the presence of silica NPs could also accelerate the production of fibrin and facilitate the coagulation system (Kudela et al., 2015; Yoshida et al., 2015). It is therefore plausible that zebrafish were likely to suffer injury after exposure to MPs and $\mathrm{Cu}-\mathrm{NPs}$, which would promote the activation and aggregation of numerous platelets due to up-regulated expression of platelet dense particles and $\alpha$ particles; and also lead to up-regulation of fibrinogen and important factors in the process of coagulation, promote the formation of fibrin clots, and ultimately enhance the hemostasis pathway to cope with external stimuli.

\section{Cell Cycle}

The DEGs under the three conditions $(0.07 \mu \mathrm{m}$ MPs, $7 \mu \mathrm{m}$ MPs, and Cu-NPs $+0.07 \mu \mathrm{m}$ MPs) were classified as cell cycle regulatory genes, checkpoint signal genes and DNA replication genes, which are indispensable for the inspection, regulation and driving of cell cycle. Cell cycle process is mainly composed of DNA replication ( $\mathrm{S}$ phase) and mitosis ( $\mathrm{M}$ phase), which are separated by G1 and G2 phases (Figure 6). The minichromosome maintenance protein (MCM) complex is a sixmembered replication helicase that controls DNA replication once in each cell cycle of eukaryotic cells. In the process of DNA replication licensing reaction, it is assembled on chromatin before replication to obtain replication capability (Maiorano, 2000; Tanaka and Araki, 2013). After being activated by S-phase protein kinases, the bound MCM complexes unwind doublestranded DNA at the starting point, recruit DNA polymerases and start DNA synthesis. Due to their crucial roles in the genome replication of proliferating cells, the down-regulation of the expressions of $m \mathrm{~cm} 3 \mathrm{l}, \mathrm{mcm} 6 \mathrm{l}$, and $\mathrm{mcm} 5$ induced by the three treatments would prevent DNA replication by inhibiting the initiation and extension of DNA replication, thereby blocking the cell cycle in $S$ phase. This has also been demonstrated in another study that the decrease of MCM proteins could reduce cell viability by inhibiting DNA replication (Lei, 2005). Furthermore, the timing of mitosis entry and the process of mitosis determine the fate of cells during development. Cyclins drive cell cycle progression by modulating the activity of cyclindependent kinases (CDKs). Cyclin A activates CDK2 and CDK1, promoting the transition from $S$ phase to $M$ phase and the initiation of mitosis, respectively (Malumbres and Barbacid, 2009). And cyclin B combines with CDK1 after the degradation of cyclin A in the prophase of mitosis, then continues to drive cells into mitosis in the form of complexes (Gurunathan et al., 2018). In the present study, the lower expression of components of cyclin A (ccna1 and ccna2) may consequently hinder the normal function of CDK2 and CDK1, and delay the progression of S and $\mathrm{G} 2 / \mathrm{M}$ phases. The suppressed expression of cyclin B (ccnb2) in three treatments would block the cell cycle progression in the G2 phase and eventually lead to apoptosis or inhibition of cell proliferation. Kim et al. (2013) further confirmed our results and reported that after exposure to PS-NPs, the cyclin levels were strongly disturbed, and DNA synthesis and cell proliferation were inhibited. By combining numerical simulation and experiment, it was found that the inhibition of cell cycle was due to the combined arrest of G1/S phase and G2/M phase transition. Similarly, it was suggested that Cu-NPs could increase cell death and decrease cell proliferation, and lead to cell cycle arrest by 


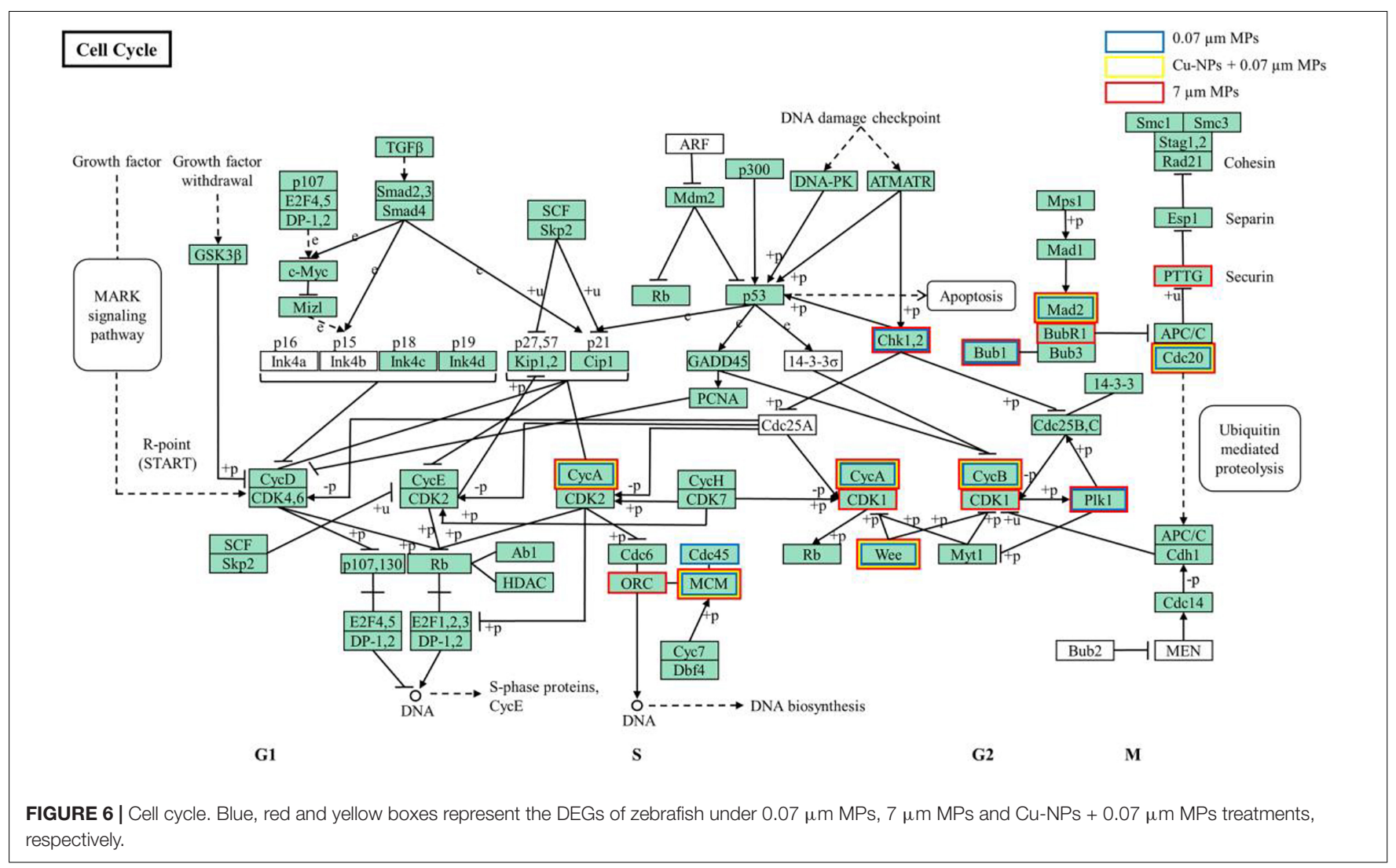

acting on G2 phase; another research has also shown that PSNPs exerted cytotoxicity by affecting the expression of cell cycle regulators (Thit et al., 2013; Maity et al., 2020).

Additionally, mitotic catastrophe is a type of cell death represented by abnormal mitotic, which is usually associated with spindle formation damage. Polo-like kinase 1 (Plk1) is essential for chromosome homeostasis and bipolar spindle assembly during mitosis. Previous studies have shown that decreased Plk1 activity in cells can induce apoptosis after delayed mitosis; it was also found that inhibition of Plk1 in zebrafish embryos resulted in dysregulation of chromosomes, failure of chromosome separation, formation of unipolar spindles, complete cessation of mitosis, and ultimately widespread cell death (Steegmaier et al., 2007; Jeong et al., 2010). Our results indicated that the down-regulated expression of plk1 induced by $0.07 \mu \mathrm{m}$ MPs and $7 \mu \mathrm{m}$ MPs could cause abnormal spindle assembly in the cell and affect the accurate arrangement and division of chromosomes. Besides, BUB1, BubR1, and Mad2 are the main components of the spindle assembly checkpoint (SAC), and they form mitotic checkpoint complex (MCC) targeting cell division cycle 20 homolog (Cdc20), which can control the transition from metaphase to anaphase of mitosis to ensure accurate separation of sister chromatids (Tang et al., 2004; Yang et al., 2012). The down-regulated expression of bub1, mad2l1, and $c d c 20$ in three treatments would weaken the function of SAC and inhibit the SAC signaling pathway, thereby increasing the error rate of chromosome separation and causing the failure of the cell mitosis process and mitotic catastrophe. Our results were corroborated by another study that exposure to MPs could cause cytogenetic abnormalities, manifested by a significant increase in mitotic aberrations (Trifuoggi et al., 2019). Bellingeri et al. (2019) also found that exposure to $\mathrm{Cu}$ and PS-MPs resulted in the formation of multinucleated cells and abnormalities in the mitotic process by observing cell morphology. Additionally, the exposure of other NPs $\left(\mathrm{TiO}_{2}\right)$ inhibited the oogenesis of zebrafish and led to cell death, which was manifested by chromatin condensation, mitochondrial swelling and mitotic catastrophe (Akbulut et al., 2017). Therefore, we believe that the exposure of PS-MPs and $\mathrm{Cu}-\mathrm{NPs}$ would hinder the transition of different phases in the cell cycle by inhibiting the expression of MCM complex and cyclins, thereby affecting the normal operation of the cell cycle and the failure of cell proliferation; it also inhibited the normal formation of spindles and spindle assembly checkpoints, which would lead to abnormal chromosome arrangement and inaccurate separation of genetic materials, and induce mitotic catastrophe.

\section{CONCLUSION}

The toxic effects of PS-MPs varied with particle size and the presence of $\mathrm{Cu}$-NPs. $7 \mu \mathrm{m}$ MPs showed slightly greater acute toxicity on zebrafish than 0.07 and $0.7 \mu \mathrm{m}$ MPs. We profiled the gene expression of zebrafish exposed to MPs (in the presence and absence of $\mathrm{Cu}-\mathrm{NPs}$ ), and provided evidence that there were two different toxic modes of exposure to MPs and $\mathrm{Cu}-\mathrm{NPs}$ on 
zebrafish. Both 0.07 and $7 \mu \mathrm{m}$ MPs acted on chromosomes and significantly affected the cell cycle process by affecting palmitoyl hydrolase activity; while $0.7 \mu \mathrm{m}$ MPs acted on extracellular space and significantly affected the activity of endopeptidase inhibitor to affect the cholesterol transport. And 0.07 and $7 \mu \mathrm{m}$ MPs dominantly affected the "cell cycle" pathway by inhibiting DNA replication, delaying the progression of S phase and G2/M phase, and affecting the accurate arrangement and separation of chromosomes; while the $0.7 \mu \mathrm{m}$ MPs activated numerous platelets to aggregate and adhere in damaged parts, enhanced the coagulation function of platelets, and promoted the formation of fibrin clots, thus abnormally activating the "hemostasis" pathway. The presence of $\mathrm{Cu}-\mathrm{NPs}$ only changed the GO enrichment results of $7 \mu \mathrm{m}$ MPs exposure, but did not significantly change the GO enrichment results affected by $0.07 \mu \mathrm{m}$ MPs and $0.7 \mu \mathrm{m}$ MPs, i.e., the combined exposure of $\mathrm{Cu}-\mathrm{NPs}$ and $7 \mu \mathrm{m}$ MPs acted on the extracellular region and significantly affected cholesterol transport by affecting the activity of cholesterol transporters, but did not significantly change the GO enrichment results affected by $0.07 \mu \mathrm{m}$ MPs and $0.7 \mu \mathrm{m}$ MPs. And the presence of $\mathrm{Cu}-$ NPs significantly changed the toxicity-related pathway induced by $7 \mu \mathrm{m}$ MPs into "hemostasis," but not for 0.07 and $0.7 \mu \mathrm{m}$ MPs. These findings help us to better understand the potential toxicity of the MPs and NPs on aquatic organisms at the transcriptome level, and provide inspiration for the combined effects of MPs and other contaminants.

\section{DATA AVAILABILITY STATEMENT}

The datasets presented in this study can be found in online repositories. The names of the repository/repositories and accession number(s) can be found below: NCBI (accession: PRJNA758596).

\section{ETHICS STATEMENT}

The animal study was reviewed and approved by North China Electric Power University.

\section{REFERENCES}

Akbulut, C., Kotil, T., Ozturk, B., and Yon, N. D. (2017). Exposure of zebrafish (Danio rerio) to titanium dioxide nanoparticle causes paraptosis: Evaluation of ovarian follicle ultrastructure. Pak. J. Zool. 49, 1077-1083. doi: 10.17582/ journal.pjz/2017.49.3.1077.1083

Austin, A. W., Patterson, S. M., and Von Kaenel, R. (2011). Hemoconcentration and hemostasis during acute stress: Interacting and independent effects. Ann. Behav. Med. 42, 153-173. doi: 10.1007/s12160-011-9274-0

Bakir, A., Rowland, S. J., and Thompson, R. C. (2014). Enhanced desorption of persistent organic pollutants from microplastics under simulated physiological conditions. Environ. Pollut. 185, 16-23. doi: 10.1016/j.envpol.2013.10.007

Batel, A., Borchert, F., Reinwald, H., Erdinger, L., and Braunbeck, T. (2018). Microplastic accumulation patterns and transfer of benzo[a]pyrene to adult zebrafish (Danio rerio) gills and zebrafish embryos. Environ. Pollut. 235, 918930. doi: 10.1016/j.envpol.2018.01.028

Bellingeri, A., Bergami, E., Grassi, G., Faleri, C., Redondo-Hasselerharm, P., Koelmans, A. A., et al. (2019). Combined effects of nanoplastics and copper

\section{AUTHOR CONTRIBUTIONS}

NG and JH conceptualized and designed the initial experiments and contributed to the writing, reviewing, and editing. NG performed and analyzed all experiments and conceptualized additional experiments. All authors provided final editing and approval for the manuscript.

\section{FUNDING}

Financial support from the Fundamental Research Funds for the State Environmental Protection Key Laboratory of Coastal Ecosystem (202108) and the Fundamental Research Funds for the Central Universities (2019MS045) are acknowledged.

\section{SUPPLEMENTARY MATERIAL}

The Supplementary Material for this article can be found online at: https://www.frontiersin.org/articles/10.3389/fmars. 2021.762530/full\#supplementary-material

Supplementary Figure 1 | Hierarchical cluster analysis of DEGs among different treatments.

Supplementary Figure 2 | Gene ontology (GO) enrichment analysis of DEGs (Supplementary Figure 2).

Supplementary Table 1 | Hydrodynamic diameter and zeta potential of Cu-NPs and PS-MPs.

Supplementary File 1 | The physical and chemical parameters of the exposure solution.

Supplementary File 2 | List of DEGs exposed to MPs with three sizes in the presence or absence of Cu-NPs.

Supplementary File 3 | List of enriched GO terms exposed to MPs with three sizes in the presence or absence of Cu-NPs.

Supplementary File 4 | List of enriched pathways exposed to MPs with three sizes in the presence or absence of Cu-NPs.

on the freshwater alga Raphidocelis subcapitata. Aquat. Toxicol. 210, 179-187. doi: 10.1016/j.aquatox.2019.02.022

Berna-Erro, A., Redondo, P. C., Lopez, E., Albarran, L., and Rosado, J. A. (2013). Molecular interplay between platelets and the vascular wall in thrombosis and hemostasis. Curr. Vasc. Pharmacol. 11, 409-430. doi: 10.2174/ 1570161111311040006

Bernardes Roda, J. F., Lauer, M. M., Risso, W. E., and Dos Reis Martinez, C. B. (2020). Microplastics and copper effects on the neotropical teleost Prochilodus lineatus: Is there any interaction? Comp. Biochem. Phys. A. 242:110659. doi: 10.1016/j.cbpa.2020.110659

Bouwmeester, H., Hollman, P. C. H., and Peters, R. J. B. (2015). Potential health impact of environmentally released micro- and nanoplastics in the human food production chain: Experiences from nanotoxicology. Environ. Sci. Technol. 49, 8932-8947. doi: 10.1021/acs.est.5b01090

Brennecke, D., Duarte, B., Paiva, F., Cacador, I., and Canning-Clode, J. (2016). Microplastics as vector for heavy metal contamination from the marine environment. Estuar. Coast. Shelf S. 178, 189-195. doi: 10.1016/j.ecss.2015.12. 003 
Chen, G. J., Ni, N. T., Zhou, J. F., Chuang, Y. J., Wang, B. H., Pan, Z. W., et al. (2011). Fibrinogen clot induced by gold-nanoparticle in vitro. J. Nanosci. Nanotechno. 11, 74-81. doi: 10.1166/jnn.2011.3571

Chen, Q., Lv, W., Jiao, Y., Liu, Z., Li, Y., Cai, M., et al. (2020). Effects of exposure to waterborne polystyrene microspheres on lipid metabolism in the hepatopancreas of juvenile redclaw crayfish, Cherax quadricarinatus. Aquat. Toxicol. 224:105497. doi: 10.1016/j.aquatox.2020.105497

Choi, D., Bang, J., Kim, T., Oh, Y., Hwang, Y., and Hong, J. (2020). In vitro chemical and physical toxicities of polystyrene microfragments in humanderived cells. J. Hazard. Mater. 400:123308. doi: 10.1016/j.jhazmat.2020.123308

Choi, J. S., Jung, Y., Hong, N. H., Hong, S. H., and Park, J. (2018). Toxicological effects of irregularly shaped and spherical microplastics in a marine teleost, the sheepshead minnow (Cyprinodon variegatus). Mar. Pollut. Bull. 129, 231-240. doi: 10.1016/j.marpolbul.2018.02.039

Clay, A. T., Lu, P., and Sharom, F. J. (2015). Interaction of the P-glycoprotein multidrug transporter with sterols. Biochem. US 54, 6586-6597. doi: 10.1021/ acs.biochem.5b00904

Cole, M., Coppock, R., Lindeque, P. K., Altin, D., Reed, S., Pond, D. W., et al. (2019). Effects of nylon microplastic on feeding, lipid accumulation, and moulting in a coldwater copepod. Environ. Sci. Technol. 53, 7075-7082. doi: 10.1021 /acs.est.9b01853

Davarpanah, E., and Guilhermino, L. (2019). Are gold nanoparticles and microplastics mixtures more toxic to the marine microalgae Tetraselmis chuii than the substances individually? Ecotox. Environ. Safe. 181, 60-68. doi: 10. 1016/j.ecoenv.2019.05.078

Ding, J., Huang, Y., Liu, S., Zhang, S., and Geng, J. (2020). Toxicological effects of nano- and micro-polystyrene plastics on red tilapia: Are larger plastic particles more harmless? J. Hazard. Mater. 396:122693. doi: 10.1016/j.jhazmat.2020. 122693

Foley, C. J., Feiner, Z. S., Malinich, T. D., and Hook, T. O. (2018). A meta-analysis of the effects of exposure to microplastics on fish and aquatic invertebrates. Sci. Total Environ. 63, 550-559. doi: 10.1016/j.scitotenv.2018.03.046

Fries, E., Dekiff, J. H., Willmeyer, J., Nuelle, M., Ebert, M., and Remy, D. (2013). Identification of polymer types and additives in marine microplastic particles using pyrolysis-GC/MS and scanning electron microscopy. Environ. Sci.-Proc. Imp. 15, 1949-1956. doi: 10.1039/c3em00214d

Ge, S., White, J. G., and Haynes, C. L. (2010). Critical role of membrane cholesterol in exocytosis revealed by single platelet study. ACS Chem. Biol. 5, 819-828. doi: $10.1021 / \mathrm{cb} 100130 \mathrm{~b}$

Geyer, R., Jambeck, J. R., and Law, K. L. (2017). Production, use, and fate of all plastics ever made. Sci. Adv. 3:e1700782. doi: 10.1126/sciadv.1700782

Golebiewska, E. M., and Poole, A. W. (2014). Secrets of platelet exocytosis - what do we really know about platelet secretion mechanisms? Brit. J. Haematol. 165, 204-216. doi: 10.1111/bjh.12682

Gu, W., Liu, S., Chen, L., Liu, Y., Gu, C., Ren, H., et al. (2020). Single-cell RNA sequencing reveals size-dependent effects of polystyrene microplastics on immune and secretory cell populations from zebrafish intestines. Environ. Sci. Technol. 54, 3417-3427. doi: 10.1021/acs.est.9b06386

Gurunathan, S., Qasim, M., Park, C., Yoo, H., Kim, J. H., and Hong, K. (2018). Cytotoxic potential and molecular pathway analysis of silver nanoparticles in human colon cancer cells HCT116. Int. J. Mol. Sci. 19:2269. doi: 10.3390/ ijms 19082269

Hamed, M., Soliman, H. A. M., Osman, A. G. M., and Sayed, A. E. D. H. (2019). Assessment the effect of exposure to microplastics in Nile Tilapia (Oreochromis niloticus) early juvenile: I. blood biomarkers. Chemosphere 228, 345-350. doi: 10.1016/j.chemosphere.2019.04.153

Hansen, B. R. H., Altin, D., Booth, A., Vang, S. H., Frenzel, M., Sørheim, K. R., et al. (2010). Molecular effects of diethanolamine exposure on Calanus finmarchicus (Crustacea: Copepoda). Aquat. Toxicol. 99, 212-222. doi: 10.1016/j.aquatox. 2010.04.018

Hartmann, N., Hüffer, T., Thompson, R. C., Hassellöv, M., Verschoor, A., Daugaard, A. E., et al. (2019). Are we speaking the same language? Recommendations for a definition and categorization framework for plastic debris. Environ. Sci. Technol. 53, 1039-1047. doi: 10.1021/acs.est.8b05297

Hueffer, T., PraetoriusP'll, A., Wagner, S., Von der Kammer, F., and Hofiliannte, T. (2017). Microplastic exposure assessment in aquatic environments: Learning from similarities and differences to engineered nanoparticles. Environ. Sci. Technol. 51, 2499-2507. doi: 10.1021/acs.est.6b04054
Jagadeeswaran, P., Gregory, M., Day, K., Cykowski, M., and Thattaliyath, B. (2005). Zebrafish: A genetic model for hemostasis and thrombosis. J. Thromb. Haemost. 3, 46-53. doi: 10.1111/j.1538-7836.2004.00999.x

Jeong, C. B., Won, E. J., Kang, H. M., Lee, M. C., Hwang, D. S., Hwang, U. K., et al. (2016). Microplastic size-dependent toxicity, oxidative stress induction, and p-JNK and p-p38 activation in the monogonont rotifer (Brachionus koreanus). Environ. Sci. Technol. 50, 8849-8857. doi: 10.1021/acs.est.6b01441

Jeong, K. H., Jeong, J. Y., Lee, H. O., Choi, E., and Lee, H. (2010). Inhibition of Plk1 induces mitotic infidelity and embryonic growth defects in developing zebrafish embryos. Dev. Biol. 345, 34-48.

Johari, V., and Loke, C. (2012). Brief overview of the coagulation cascade. DM-Dis. Mon. 58, 421-423. doi: 10.1016/j.disamonth.2012.04.004

Kannel, W. B. (2005). Overview of hemostatic factors involved in atherosclerotic cardiovascular disease. Lipids 40, 1215-1220. doi: 10.1007/s11745-005-1488-8

Khokhlova, O. N., Tukhovskaya, E. A., Kravchenko, I. N., Sadovnikova, E. S., Pakhomova, I. A., Kalabina, E. A., et al. (2017). Using tiletaminezolazepam-xylazine anesthesia compared to $\mathrm{CO}_{2}$-inhalation for terminal clinical chemistry, hematology, and coagulation analysis in mice. J. Pharmacol. Tox. Met. 84, 11-19. doi: 10.1016/j.vascn.2016.10.005

Kim, D., Finkenstaedt-Quinn, S., Hurley, K. R., Buchman, J. T., and Haynes, C. L. (2014). On-chip evaluation of platelet adhesion and aggregation upon exposure to mesoporous silica nanoparticles. Analyst 139, 906-913. doi: 10. 1039/c3an01679j

Kim, J. A., Aberg, C., de Carcer, G., Malumbres, M., Salvati, A., and Dawson, K. A. (2013). Low dose of amino-modified nanoparticles induces cell cycle arrest. ACS Nano 7, 7483-7494. doi: 10.1021/nn403126e

Krupiczojc, M. A., Scotton, C. J., and Chambers, R. C. (2008). Coagulation signalling following tissue injury: Focus on the role of factor Xa. Int. J. Biochem. Cell B. 40, 1228-1237. doi: 10.1016/j.biocel.2008.02.026

Kudela, D., Smith, S. A., May-Masnou, A., Braun, G. B., Pallaoro, A., Nguyen, C. K., et al. (2015). Clotting activity of polyphosphate-functionalized silica nanoparticles. Angew. Chem. Int. Edit. 54, 4018-4022. doi: 10.1002/anie. 201409639

Lasne, D., Jude, B., and Susen, S. (2006). From normal to pathological hemostasis. Can. J. Anaesth. 53, S2-S11.

Le, L., Liu, M., Song, Y., Lu, S., Hu, J., Cao, C., et al. (2018). Polystyrene (nano)microplastics cause size-dependent neurotoxicity, oxidative damage and other adverse effects in Caenorhabditis elegans. Environ. Sci.-Nano 5, 20092020. doi: 10.1039/c8en00412a

Lebreton, L. C. M., Van der Zwet, J., Damsteeg, J., Slat, B., Andrady, A., and Reisser, J. (2017). River plastic emissions to the world's oceans. Nat. Commun. 8:15611.

Lee, K., Shim, W. J., Kwon, O. Y., and Kang, J. (2013). Size-dependent effects of micro polystyrene particles in the marine copepod Tigriopus japonicus. Environ. Sci. Technol. 47, 11278-11283. doi: 10.1021/es401932b

Lehner, R., Weder, C., Petri-Fink, A., and Rothen-Rutishauser, B. (2019). Emergence of nanoplastic in the environment and possible impact on human health. Environ. Sci. Technol. 53, 1748-1765. doi: 10.1021/acs.est.8b05512

Lei, M. (2005). The Mcm complex: Its role in DNA replication and implications for cancer therapy. Curr. Cancer Drug Tar. 5, 365-380. doi: 10.2174/ 1568009054629654

Li, P., Zou, X., Wang, X., Su, M., Chen, C., Sun, X., et al. (2020). A preliminary study of the interactions between microplastics and citrate-coated silver nanoparticles in aquatic environments. J. Hazard. Mater. 385:121601.

Lu, Y., Zhang, Y., Deng, Y., Jiang, W., Zhao, Y., Geng, J., et al. (2016). Uptake and accumulation of polystyrene microplastics in zebrafish (Danio rerio) and toxic effects in liver. Environ. Sci. Technol. 50, 4054-4060. doi: 10.1021/acs.est. $6 \mathrm{~b} 00183$

Luo, T., Zhang, Y., Wang, C., Wang, X., Zhou, J., Shen, M., et al. (2019). Maternal exposure to different sizes of polystyrene microplastics during gestation causes metabolic disorders in their offspring. Environ. Pollut. 255:113122. doi: 10. 1016/j.envpol.2019.113122

Machado, A. A. D. S., Kloas, W., Zarfl, C., Hempel, S., and Rillig, M. C. (2018). Microplastics as an emerging threat to terrestrial ecosystems. Global Change Biol. 24, 1405-1416. doi: 10.1111/gcb.14020

Maiorano, D. (2000). Stepwise regulated chromatin assembly of Mcm2-7 proteins. J. Biol. Chem. 275, 8426-8431. doi: 10.1074/jbc.275.12.8426

Maity, S., Chatterjee, A., Guchhait, R., De, S., and Pramanick, K. (2020). Cytogenotoxic potential of a hazardous material, polystyrene microparticles 
on Allium cepa L. J. Hazard. Mater. 385:121560. doi: 10.1016/j.jhazmat.2019. 121560

Malumbres, M., and Barbacid, M. (2009). Cell cycle, CDKs and cancer: A changing paradigm. Nat. Rev. Cancer 9, 153-166. doi: 10.1038/nrc2602

Medvedev, I. N., Zavalishina, S. Y., Krasnova, E. G., and Belova, T. A. (2010). Mechanisms of hemostasis in living beings. Mezhdunarodnyi vestnik veterinarii $1,52-55$.

OECD. (2019). Test No. 203: Fish, Acute Toxicity Test. Paris: OECD.

Pico, Y., Alfarhan, A., and Barcelo, D. (2018). Nano and mciroplastic analysis: Focus on remediation technologies and occurrence in freshwater ecosystems. Trac-Trend. Anal. Chem. 113, 409-425. doi: 10.1016/j.trac.2018.08.022

Prata, J. C., Lavorante, B. R. B. O., Montenegro, M. D. C. B., and Guilhermino, L. (2018). Influence of microplastics on the toxicity of the pharmaceuticals procainamide and doxycycline on the marine microalgae Tetraselmis chuii. Aquat. Toxicol. 197, 143-152. doi: 10.1016/j.aquatox.2018.02.015

Qiao, R., Lu, K., Deng, Y., Ren, H., and Zhang, Y. (2019). Combined effects of polystyrene microplastics and natural organic matter on the accumulation and toxicity of copper in zebrafish. Sci. Total Environ. 682, 128-137. doi: 10.1016/j. scitotenv.2019.05.163

Rist, S., Baun, A., and Hartmann, N. B. (2017). Ingestion of micro- and nanoplastics in Daphnia magna - Quantification of body burdens and assessment of feeding rates and reproduction. Environ. Pollut. 228, 398-407. doi: 10.1016/j.envpol. 2017.05.048

Sanganyado, E., Rajput, I. R., and Liu, W. (2018). Bioaccumulation of organic pollutants in Indo-Pacific humpback dolphin: A review on current knowledge and future prospects. Environ. Pollut. 237, 111-125. doi: 10.1016/j.envpol.2018. 01.055

Schirinzi, G. F., Perez-Pomeda, I., Sanchis, J., Rossini, C., Farre, M., and Barcelo, D. (2017). Cytotoxic effects of commonly used nanomaterials and microplastics on cerebral and epithelial human cells. Environ. Res. 159, 579-587. doi: 10.1016/j. envres.2017.08.043

Sendra, M., Isabel Carrasco-Braganza, M., Maria Yeste, P., Vila, M., and Blasco, J. (2020). Immunotoxicity of polystyrene nanoplastics in different hemocyte subpopulations of Mytilus galloprovincialis. Sci. Rep. UK 10:86371.

Steegmaier, M., Hoffmann, M., Baum, A., Lénárt, P., Petronczki, M., Ák, M. K., et al. (2007). BI 2536, a potent and selective inhibitor of polo-like kinase 1, inhibits tumor growth in vivo. Curr. Biol. 17, 316-322. doi: 10.1016/j.cub.2006. 12.037

Sussarellu, R., Suquet, M., Thomas, Y., Lambert, C., Fabioux, C., Pernet, M. E. J., et al. (2016). Oyster reproduction is affected by exposure to polystyrene microplastics. P. Natl. Acad. Sci. USA 113, 2430-2435. doi: 10.1073/pnas. 1519019113

Tanaka, S., and Araki, H. (2013). Helicase activation and establishment of replication forks at chromosomal origins of replication. Csh. Perspect. Biol. 5:a10371.

Tang, Z., Shu, H., Oncel, D., Chen, S., and Yu, H. (2004). Phosphorylation of Cdc20 by Bub1 provides a catalytic mechanism for APC/C inhibition by the spindle checkpoint. Mol. Cell 16, 387-397. doi: 10.1016/j.molcel.2004.09.031

Thit, A., Selck, H., and Bjerregaard, H. F. (2013). Toxicity of CuO nanoparticles and $\mathrm{Cu}$ ions to tight epithelial cells from Xenopus laevis (A6): Effects on proliferation, cell cycle progression and cell death. Toxicol. In Vitro 27, 15961601. doi: 10.1016/j.tiv.2012.12.013

Trevisan, R., Voy, C., Chen, S., and Di Giulio, R. T. (2019). Nanoplastics decrease the toxicity of a complex PAH mixture but impair mitochondrial energy production in developing zebrafish. Environ. Sci. Technol. 53, 8405-8415. doi: 10.1021/acs.est.9b02003

Trifuoggi, M., Pagano, G., Oral, R., Pavicic-Hamer, D., Buric, P., Kovacic, I., et al. (2019). Microplastic-induced damage in early embryonal development of sea urchin Sphaerechinus granularis. Environ. Res. 179:108815. doi: 10.1016/j. envres.2019.108815

van der Poll, T., and Parker, R. I. (2020). Platelet activation and endothelial cell dysfunction. Crit. Care Clin. 36:233. doi: 10.1016/j.ccc.2019. 11.002
Vo, A. H., Swaroop, A., Liu, Y., Norris, Z. G., and Shavit, J. A. (2013). Loss of fibrinogen in zebrafish results in symptoms consistent with human hypofibrinogenemia. PLoS One 8:e74682. doi: 10.1371/journal.pone.0074682

Wagenaar, G. T. M., Uhrin, P., Weipoltshammer, K., Almeder, M., Hiemstra, P. S., Geiger, M., et al. (2010). Expression patterns of protein C inhibitor in mouse development. J. Mol. Histol. 41, 27-37.

Watts, A. J. R., Urbina, M. A., Corr, S., Lewis, C., and Galloway, T. S. (2015). Ingestion of plastic microfibers by the crab Carcinus maenas and its effect on food consumption and energy balance. Environ. Sci. Technol. 49, 14597-14604. doi: 10.1021/acs.est.5b04026

Wright, S. L., Thompson, R. C., and Galloway, T. S. (2013). The physical impacts of microplastics on marine organisms: A review. Environ. Pollut. 178, 483-492. doi: 10.1016/j.envpol.2013.02.031

Wu, F., Harper, B. J., Crandon, L. E., and Harper, S. L. (2020). Assessment of $\mathrm{Cu}$ and $\mathrm{CuO}$ nanoparticle ecological responses using laboratory small-scale microcosms. Environ. Sci.-Nano 7, 105-115. doi: 10.1039/c9en01026b

Xia, X., Sun, M., Zhou, M., Chang, Z., and Li, L. (2020). Polyvinyl chloride microplastics induce growth inhibition and oxidative stress in Cyprinus carpio var. larvae. Sci. Total Environ. 716:136479. doi: 10.1016/j.scitotenv.2019.136479

Xu, J., Hedberg, C., Dekker, F. J., Li, Q., Haigis, K. M., Hwang, E., et al. (2012). Inhibiting the palmitoylation/depalmitoylation cycle selectively reduces the growth of hematopoietic cells expressing oncogenic Nras. Blood 119, 10321035. doi: 10.1182/blood-2011-06-358960

Yang, C. Y., Wang, H. B., Xu, Y. R., Brinkman, K. L., Ishiyama, H., Wong, S. T. C., et al. (2012). The kinetochore protein Bubl participates in the DNA damage response. DNA Repair 11, 185-191. doi: 10.1016/j.dnarep.2011.10.018

Yoshida, T., Yoshioka, Y., Morishita, Y., Aoyama, M., Tochigi, S., Hirai, T., et al. (2015). Protein corona changes mediated by surface modification of amorphous silica nanoparticles suppress acute toxicity and activation of intrinsic coagulation cascade in mice. Nanotechnology 26:245101. doi: 10.1088/ 0957-4484/26/24/245101

Yu, P., Liu, Z., Wu, D., Chen, M., Lv, W., and Zhao, Y. (2018). Accumulation of polystyrene microplastics in juvenile Eriocheir sinensis and oxidative stress effects in the liver. Aquat. Toxicol. 200, 28-36. doi: 10.1016/j.aquatox.2018.04. 015

Zhang, F., Man, Y. B., Mo, W. Y., Man, K. Y., and Wong, M. H. (2020). Direct and indirect effects of microplastics on bivalves, with a focus on edible species: A mini-review. Crit. Rev. Env. Sci. Tec. 50, 2109-2143. doi: 10.1080/10643389. 2019.1700752

Zhang, J., Huang, Y., Chen, J., Zhu, H., and Whiteheart, S. W. (2018). Dynamic cycling of t-SNARE acylation regulates platelet exocytosis. J. Biol. Chem. 293, 3593-3606. doi: 10.1074/jbc.ra117.000140

Zhu, X., Zhao, W., Chen, X., Zhao, T., Tan, L., and Wang, J. (2020). Growth inhibition of the microalgae Skeletonema costatum under copper nanoparticles with microplastic exposure. Mar. Environ. Res. 158:105005. doi: 10.1016/j. marenvres.2020.105005

Conflict of Interest: The authors declare that the research was conducted in the absence of any commercial or financial relationships that could be construed as a potential conflict of interest.

Publisher's Note: All claims expressed in this article are solely those of the authors and do not necessarily represent those of their affiliated organizations, or those of the publisher, the editors and the reviewers. Any product that may be evaluated in this article, or claim that may be made by its manufacturer, is not guaranteed or endorsed by the publisher.

Copyright (c) 2021 Gao, Huang, Xing, Zhang and Hou. This is an open-access article distributed under the terms of the Creative Commons Attribution License (CC BY). The use, distribution or reproduction in other forums is permitted, provided the original author(s) and the copyright owner(s) are credited and that the original publication in this journal is cited, in accordance with accepted academic practice. No use, distribution or reproduction is permitted which does not comply with these terms. 